\title{
UTILIZAÇÃO DA ULTRASSONOGRAFIA POR VIA TRANSRETAL EM VACAS DA RAÇA GIROLANDO PARA ACOMPANHAMENTO DO DESENVOLVIMENTO EMBRIONÁRIO E/ OU FETAL 26 A 181 DIAS DE GESTAÇÃO
}

MENEZES, Matheus de Castro ${ }^{1}$

LÉGA, Elzylene ${ }^{2}$

COELHO, Luciano Augusto Ferreira ${ }^{3}$

Recebido em: 2010-10-10

Aprovado em: 2011-05-25

ISSUE DOI: $10.3738 / 1982.2278 .492$

\begin{abstract}
RESUMO: Neste estudo foram utilizadas 11 vacas da raça Girolando, com objetivo de estudar o início do período gestacional em ruminantes, segundo as técnicas de diagnóstico precoce de gestação e fetometria, através da ultrassonografia em modo-B. Foram empregadas técnicas de inseminação artificial convencional (IA) ou em tempo fixo (IATF), sendo que a data da inseminação foi considerada o dia 0 (D-0). Foi avaliado o momento exato para diagnóstico gestacional através da técnica ultrassonográfica transretal. As mensurações fetais desde o diagnóstico gestacional até o sexto mês de gestação foram registradas. Assim verificou-se que o diagnóstico de gestação em bovinos pode ser dado aos 30 dias e que, a partir da visualização do feto, a fetometria pode ser realizada, possibilitando acompanhar o desenvolvimento fetal, na qual obtivemos as medidas dos seguintes parâmetros fetométricos; vesícula gestacional (VG), diâmetro do placentônio (PLA), comprimento crânio-caudal (CCC), comprimento da escápula (CE), comprimento do fêmur (CF), comprimento do ílio (CI), comprimento do rádio e ulna $(\mathrm{CR})$, comprimento da tíbia $(\mathrm{CT})$, comprimento do úmero $(\mathrm{CU})$, diâmetro abdominal longitudinal (DAL), diâmetro abdominal transversal (DAT), diâmetro biparietal (DBP), diâmetro inter-orbital (DIO), diâmetro das falanges (FL) diâmetro ocular (DO), diâmetro occípto-frontal (DOF), diâmetro do tórax, frequiência cardíaca (FC), comprimento de metacarpo (MEC) e metatarso (MET).
\end{abstract}

Palavras-Chave: Fetometria. Gestação. Bovino.

SUMMARY: In this study 11 cows of the Girolando race had been used, with objective to study the beginning of the gestacional period in ruminants, according to techniques of precocious diagnosis of gestation and fetometry, through the ultrassonography in way-b. Techniques of conventional artificial insemination had been used (I.A.) or in fixed time (I.A.T.F.), where the date of the insemination was considered day 0 (D0). In the present study the accurate moment for gestacional diagnosis through the transretal technique was evaluated. The fetais mensurament since the gestacional diagnosis until sixth month of gestation had been registered. Thus it was verified that the gestation diagnosis can be given to the 30 days and that, from the visualization of the embryo, the fetometria can be carried through, making possible to follow the fetal development, which we got the measures of the following fetometry parameters; gestacional vesicle (VG), diameter of placentônio (PLA), length skull-volume (CCC), length of the spike (CE), length of fêmur (CF), length of ilio (CI), length of rádio and ulna (CR), length of tíbia (CT), length of úmero (CU), longitudinal abdominal diameter (DAL), transversal abdominal diameter (DAT), biparietal diameter (DBP), inter-orbital diameter (DIO), falanges diameter (FL) orbital diameter (DO), occípto-frontal diameter (DOF), diameter of the thorax (DT), cardiac frequency (FC), length of metacarpo (MEC) and metatarso (MET).

Keywords: Fetometry. Pregnancy. Bovine.

\section{INTRODUÇÃO}

Os bovinos domésticos pertencem à família Bovidae e foram domesticados para

\footnotetext{
${ }^{1}$ Aprimorando do Hospital Veterinário FAFRAM, Ituverava- SP

${ }^{2}$ Docente do Curso de Medicina Veterinária FAFRAM, Ituverava-SP

${ }^{3}$ Graduando do Curso de Medicina Veterinária FAFRAM, Ituverava-SP
}

Nucleus Animalium, v.3,n.1,maio 2011 
tração, produção de leite e carne, dentre aqueles com aptidão leiteira, destaca-se a raça Girolando. Segundo a Associação Brasileira dos Criadores de Girolando (2005), as primeiras notícias do surgimento da raça, data-se da década de 40. Pelos anseios dos criadores brasileiros, começou a ser praticado o cruzamento do Gir com o Holandês intensamente, procurando que as duas raças se complementassem com rusticidade e produtividade. A multiplicação desses animais, mesmo desordenadamente, foi acelerada pela alta produtividade e eficiência reprodutiva.

Durante o processo de domesticação, tanto para bovinos de leite, quanto para bovinos de corte, os animais foram submetidos ao acasalamento sem que houvesse um determinado período, facilitando assim a ovulação e concepção ao longo do ano, sendo que o intervalo de parto considerado ótimo para o gado leiteiro e gado de corte é de 12 meses, ou seja, parições uma vez ao ano, o que pode ser otimizado com biotécnicas de reprodução tais como IA e IATF e, como forma de avaliar a eficiência de todas elas, o diagnóstico de gestação, cuja importância tem crescido principalmente em criações em que o aspecto econômico para produção é considerado, sendo aproveitando as características genéticas de um fêmea. A identificação precoce da gestação permite a redução do intervalo entre partos; a realização de novo acasalamento ou inseminação artificial nas fêmeas não gestantes ainda dentro da estação reprodutiva; diagnóstico de problemas relacionados à fertilidade e descarte precoce de fêmeas inférteis ou estéreis, além de possibilitar alimentação diferenciada para fêmeas gestantes e não gestantes no terço final da gestação.

O conhecimento da idade do concepto é importante subsídio na clínica veterinária. Para tanto, já existem padrões biométricos fetais nos diferentes estádios de gestação para grandes animais, pequenos ruminantes e suínos analisados por ultrassonografia, baseados no tamanho e características gerais de desenvolvimento, cujas medidas permitem a inferência da idade do concepto in vivo através de uma técnica chamada de fetometria ultrassônica ou biometria fetal, porém deve ser realizada com precisão para que não haja interferência na avaliação da morfologia fetal (WOLF; GABALDI, 2002).

É importante frisar que a ótima aproximação da idade fetal em bovinos depende do estádio da gestação e da acessibilidade às estruturas do concepto (KÄHN, 1994).

As fêmeas bovinos são poliéstricas, apresentando estros em intervalos regulares médios de 21 dias. Nesta espécie, o processo de foliculogênese tem início com a formação dos folículos durante a vida fetal, ou seja, ao nascimento, as crias já têm estabelecido o número de folículos primordiais nas suas gônadas, os quais compõem o estoque de folículos formado durante a fase fetal e que vão se desenvolver durante a vida reprodutiva da fêmea (GONÇALVES et al., 2008) 
Em bovinos, a técnica de palpação retal se baseia na capacidade de detectar a presença de um feto crescendo em um dos cornos uterinos por meio da inserção do braço no reto da vaca (Figura 1). É possível detectar uma diferença no tamanho dos dois cornos uterinos, porém é uma técnica que depende diretamente da habilidade do examinador sendo prática segura, a partir do $40^{\circ}$ dia após a inseminação artificial ou monta natural (BALL; PETERS, 2006). Em 1980, o emprego da ultrassonografia possibilitou o diagnóstico mais precoce relacionada a gestação (GONÇALVES et al., 2008).

O período de desenvolvimento intra-uterino é chamado prenhez ou gestação e está relacionado, em primeiro lugar, com a nutrição do concepto em desenvolvimento e com as adaptações maternas dirigidas a essa finalidade (JAINUDEEN; HAFEZ, 2004).

O estudo da gestação, desde sua detecção precoce até a determinação da data de parto tem como principais benefícios a programação e a diferenciação do rebanho; o diagnóstico de problemas relacionados à fertilidade ou a defeitos congênitos; o descarte precoce de fêmeas inférteis e a suplementação alimentar de fêmeas, principalmente no terço final da gestação (SIMPLÍCIO, 2000; SALLES, 2001 apud LÉGA, et al., 2007).

O tempo fisiológico de gestação varia de 280 e 285 dias na vaca, sendo decorrente de influência genética tanto da matriz quanto do reprodutor (BALL; PETERS, 2006), fatores fetais, sendo considerado o números e o sexo do concepto, fatores endócrinos e fatores ambientais (TONIOLLO; VICENTE, 1993).

Segundo Prestes; Alvarenga (2006), a implantação do embrião inicia-se nos bovinos ao redor dos 11 dias após a clivagem e termina perto dos 40 dias de gestação e trata-se do contato físico, após a dissolução da zona pelúcida, entre o trofoblasto e o endométrio.

Em espécies onde ocorre um alongamento de blastocisto antes da implantação, como nos ruminantes, esta ocorre em sítios específicos da parede uterina, chamados de carúnculas.

Tufos isolados de vilos coriônicos ramificados chamados de cotilédones, unem-se a proeminências endometriais ovais aglandulares pré-formadas, as carúnculas. As estruturas maternas (carúncula) e fetais (cotilédone) combinam-se para formar os placentônios nos ruminantes. Os placentônios são os únicos pontos de trocas materno-fetais, nesse tipo de placenta denominada placenta cotiledonária. A placenta é um órgão intermediário entre a mãe e o concepto, servindo para suplemento de oxigênio e nutrientes, remoção de detritos metabólicos, produção e secreção de hormônios e fatores de crescimento fetal (VICENTE, 1993; PRESTES; ALVARENGA, 2006; TONIOLLO).

Placentônios são rotineiramente encontrados entre 26-28 dias após o acasalamento e aparecem como estruturas de densidade ecogênica na parede uterina (BUCKRELL et al., 1986). Apresentam-se como estruturas hiperecogênicas que se destacam no fundo de imagens 
anecóicas, representado pelo fluido uterino. Seu aspecto depende do ângulo de secção e estádio de desenvolvimento. Através de secção sagital assumem a forma de "C", foice ou cúpula. Em secção horizontal, assumem forma de anel, apresentando centro hipoecogênico (HAIBEL, 1990).

A placenta se origina da porção trofoblástica do embrião e sua ação sobre o útero resulta na placenta materna. A morfogênese da placenta envolve os seguintes componentes segundo Toniollo (1993): âmnio que envolve o concepto; saco vitelínico que é o precursor da vesícula umbilical; alantóide, que é o reservatório de urina e córion que é a membrana mais externa.

A placenta é órgão altamente eficiente na manutenção da adequada oxigenação fetal, mesmo por ocasião do parto, em que forças expulsivas alteram a dinâmica circulatória e o concepto se encontra suficientemente protegido contra anóxia. A deglutição regular do líquido amniótico durante a gestação propicia absorção de água, eletrólitos, glucose, uréia e hormônios, além do acumulo de resíduos celulares e pigmentos biliares no intestino grosso (mecônio) que o feto só expele após o nascimento (TONIOLLO, 1993).

A ultrassonografia, também denominada ecografia, é atualmente um método de diagnóstico largamente utilizado na Medicina Veterinária em todas as espécies. O uso desta técnica nos animais de produção teve início nos anos 80 com a espécie eqüina, expandindo-se depois para outras áreas (ARAÚJO; MOURA, 2009).

Kähn (1994) descreveu a ultrassonografia como ondas que penetram nos tecidos sendo devolvidas como ecos, os quais são captados pelo mesmo cristal e transformados no aparelho em pontos brilhosos que aparecem no monitor. Quanto maior a reflexão por parte do tecido, mais brilhantes são os pontos formados. Cada tecido tem diferentes graus de econgenicidade (geração de eco) e, segundo a quantidade de ecos que refletem dependendo da impedância do tecido, podem ser denominados de hiper ou hipoecogênicos ou ainda, anecogênicos (sem ecogenicidade). A imagem anecóica formada apresenta uma escala de coloração que varia do cinza ao preto, esta última, característica dos líquidos límpidos. A imagem hiperecóica apresenta um branco intenso como no caso dos ossos compactos, os quais refletem todos os ecos e podem também dar imagem espelhada e artefatos ( imagens não reais ). Para fêmeas bovinas, empregam-se sondas transretais com freqüência de 5.0, 6.0 e $8.0 \mathrm{MHz}$, sendo estas selecionadas em função do tipo de exame a ser realizado (diagnóstico de prenhez ou monitoramento da atividade ovariana).

A ultrassonografia tem sido amplamente utilizada na reprodução e obstetrícia como uma técnica que permite diagnóstico de gestação e monitoração intra-uterina dos conceptos bovinos, sem colocar em risco a gestação para avaliação do escore ovariano; para recuperação 
de oócitos por punção folicular e para diagnósticos de afecções reprodutivas. As avaliações ultrassonográficas da viabilidade e desenvolvimento normal intra-uterino durante o estádio embrionário tornam-se possíveis a partir do momento da detecção ecográfica do embrião e dos seus batimentos cardíacos, assim como durante a fase fetal, a partir dos 45 dias de gestação. No entanto, a monitoração fetal está limitada quer pelo pequeno campo de exploração dos feixes de ultrassons, tanto em largura como em profundidade, quer pela diminuição da acessibilidade fetal, principalmente a partir dos quatro meses de gestação (SIMÕES, 1998).

Estas avaliações permitem, ainda, determinar a idade e sexo fetais, diagnosticar precocemente malformações e possibilitar investigações de fatores que influenciam o desenvolvimento intra-uterino do concepto. Para a realização da fetometria e a determinação da idade gestacional, utilizam-se alguns parâmetros como: comprimento crânio-caudal (CCC), mensurado a partir da extremidade superior do crânio até a primeira vértebra coccígea; diâmetro biparietal (DBP), avaliado como a distância entre os ossos biparietais no corte transversal e a freqüência cardíaca (FC), aferida em modo-M (RAMOS et al., 2007).

Em adição ao diagnóstico de gestação, observações por ultrassonografia são auxiliares para diagnóstico precoce de hidropsias (JONES; FECTEAU, 1995), malformações fetais, mumificação fetal e diferenciação entre gestação e piometra (HAIBEL, 1990) ou hidrometra (PIETERSE; TAVERNE, 1986). O útero aparece distendido com fluido anecogênico na hidrometra e com fluido ecogênico cinza e branco na piometra, sem aparência de placentônios ou fetos. A mumificação fetal é caracterizada pela presença de uma imagem densa, hiperecóica e sem fluido (ISHWAR, 1995).

As maiores vantagens da técnica em modo-B é a avaliação em tempo real e a capacidade de registrar imagens paradas, possibilitando a identificação e mensurações dos tecidos o que oferece meio eficaz, rápido, satisfatório e prático no diagnóstico (ISHWAR, 1995).

A ultrassonografia pode mostrar resultado precoce e confiável para diagnóstico gestacional em bovinos entre o $19^{\circ}$ e o $27^{\circ}$ dia após o acasalamento, porém para obtenção de Medidas fetométricas, bem como determinação do sexo fetal, o exame só é preciso a partir do $40^{\circ}$ dia gestacional (HUSSEIN, 2008)

Moreno et al. (1996), estudaram a freqüência cardíaca e parâmetros fetométricos, sendo possível aferir comprimento de ossos longos, distância inter-orbital, medidas do crânio, diâmetros do tórax e do abdômen, relacionando todos os valores com os dias antes do parto, revelando que a fetometria é mais apropriada para a determinação da idade gestacional. 
Uma vez visualizadas as estruturas ósseas, torna-se possível calcular a idade gestacional por meio de mensurações fetais, permitindo prever a data do parto e manter a fêmea sob manejo adequado (REICHLE; HABEL, 1991; BRETZLAFF et al., 1993).

A ultrassonografia pode estabelecer medidas e determinar a idade fetal em várias espécies, tanto doméstica, como selvagens. Os resultados ultrassonográficos indicam que as medidas encontradas constituem uma ferramenta valiosa para tal estimativa em qualquer faze da prenhez de Lhamas (Lama glama) e Alpacas (Lama pacos) (GAZITÚA, 2000).

Segundo estudos realizados em suínos, o tempo mínimo de gestação das fêmeas suínas para diagnóstico realizado através da ultrassonografia transabdominal foi de 20 dias após acasalamento natural, ou inseminação artificial. Mostrando ser um exame rápido, de alta acurácia, e que pode ser utilizado como método auxiliar para melhorar a eficiência reprodutiva nesta espécie (ABUD et al., 2009).

Karen et al. (2008) citaram que a idade do concepto em pequenos ruminantes, pode ser estimada através da mensuração de parâmetros como diâmetro biparietal, comprimento crânio caudal, diâmetro do tórax, diâmetro dos placentônios, comprimento do fêmur e diâmetro do cordão umbilical.

É importante frisar que a ótima aproximação da determinação da idade fetométrica de fetos bovinos depende do estádio da gestação e da acessibilidade das partes do corpo fetal, podendo ser melhorada pela combinação de vários parâmetros. O estômago e a fenda dos cascos são observados, respectivamente, aos 40 e de 42 a 49 dias, juntamente com o início dos movimentos dos membros e da cabeça. Com 35 a 40 dias de gestação, iniciam os centros de ossificação, sendo que aos 51 a 55 dias aparecem as costelas; aos 61 a 65 dias, mandíbula, vértebras cervicais, torácicas, lombares e sacrais e ossos longos; aos 66 a 70 dias a escápula, o ílio e o ísquio; aos 71 a 80 dias, a cauda e, aos 81 a 85 dias as falanges e o esterno, antes da calcificação total, a qual se torna mais intensa ao redor dos 180 dias de gestação (KÄHN, 1994).

Em média, com 20 a 22 dias de gestação é possível identificar o embrião, em forma de "C" até o $30^{\circ}$ dia, com aproximadamente $5 \mathrm{~mm}$ de comprimento no seu maior eixo, e seus batimentos cardíacos variando de 150 a 188 batimentos por minuto, o que diminui com a progressão da gestação, permitindo, assim, a avaliação de sua viabilidade. Neste momento (23 dias), a vesícula gestacional preenchida com o âmnion já se encontra bem distendida com diâmetro de 3 a $5 \mathrm{~mm}$ e é facilmente observada na ultrassonografia transretal em bovinos. A visualização do embrião nesta fase inicial nem sempre é possível devido à dificuldade de diferenciá-lo, algumas vezes, da parede uterina com a qual ele está em contato, mas, posteriormente, é de fácil identificação, apresentando um crescimento de $1 \mathrm{~mm} / \mathrm{dia}$, entre os 
dias 20 e 50 da gestação. No dia 25 de gestação, a vesícula apresenta um diâmetro de 10mm, alcançando o corpo do útero e, as pregas uterinas a dividem em lojas. No $30^{\circ}$ dia, o diâmetro da vesícula já é de 18 a $20 \mathrm{~mm}$ e, já pode ser visualizado no corno uterino contralateral com um diâmetro de 4 a 8mm, quando o feto pode ser bem visualizado em forma de "L", com $12 \mathrm{~mm}$ de tamanho e envolto por uma fina linha ecogênica, o âmnion. Com 29 a 33 dias, as cavidades oculares podem ser observadas como áreas anecóicas esféricas em cada lado do crânio; com 29 a 39 dias de gestação os membros anteriores são identificados e, com 33 a 38 dias, os placentomas já são evidentes próximos ao concepto, como elevações semicirculares (WOLF; GABALDI, 2002).

A visualização das estruturas e órgãos fetais pela ultrassonografia vai ocorrendo com o avanço da gestação, permitindo a avaliação de suas características. A partir dos 30 dias de gestação torna-se possível à mensuração de uma variedade de parâmetros e, a partir do segundo trimestre de gestação, todos os órgãos podem ser avaliados. Além disso, entre o segundo e o terceiro trimestre, as característica observáveis do ambiente uterino são os múltiplos placentônios e a hiperecogenicidade pela riqueza em células do fluido amniótico em detrimento à hipoecogenicidade do fluido alantóide (LÉGA, 2007).

Para se determinar corretamente a posição das porções avaliadas, há a denominação de três planos de exame: secção sagital ou mediana, secção horizontal e secção cruzada ou transversal. Em semelhança à radiologia, na ultrassonografia há também a descrição do direcionamento das ondas sonoras que atravessam o corpo avaliado: raio sonoro dorso-ventral e ventrolateral (KÄHN, 1994).

O olho é o órgão mais freqüentemente avaliado para a fetometria durante todos os estádios da gestação, bem como, semelhantemente, a crânio, que é avaliado até o final do sétimo mês. Já a distância crânio-caudal (distância entre o osso occipital e a primeira vértebra da cauda) somente pode ser mensurada por um breve período, devido ao limitado tamanho da imagem mostrada na tela $(10 \mathrm{~cm})$, apesar de ser um dos mais acurados para a determinação da idade fetal. No entanto, outros órgãos podem ser mensurados, mas com dificuldades e por períodos limitados (WOLF; GABALDI, 2002).

Segundo Kähn (1989), até o final do $4^{\circ}$ mês de gestação, pode-se observar os membros torácicos e pélvicos frequentemente durante o $5^{\circ}, 6^{\circ}$ e $7^{\circ}$ meses, os membros pélvicos podem ser observados em $25 \%$ dos casos, embora encontrados raramente em todos os animais. Cabeça tórax, abdômen e pélve podem ser facilmente acessíveis através da ultrassonografia transretal, durante os primeiros quatro meses. Entre o $5^{\circ}$ e $7^{\circ}$ meses, as regiões torácicas, abdominais e pélvicas podem ser observadas pelo menos em um terço dos casos. A cabeça pode ser acessível em cerca de $80 \%$ dos casos analisados durante toda prenhez. 
Barros (1997), estudando fetos bovinos, refere que o período ideal para o diagnóstico do sexo fetal com máxima acurácia é ao redor de 60 dias, mas com possibilidade entre 53 e 120 dias. A apresentação do feto em plano longitudinal látero-lateral facilita o diagnóstico dos sexos, pois permite a observação, em uma única imagem, dos membros torácicos, do tórax, do cordão umbilical, dos membros pélvicos, da cauda e do tubérculo genital, visualizando em muitos casos a rafe ano-genital e a bolsa escrotal nos machos e as mamas nas fêmeas. No plano longitudinal dorso-ventral há uma ampla visão do feto, o que facilita o diagnóstico, favorecendo tanto os machos quanto as fêmeas.

A sexagem em bovinos antes do $45^{\circ}$ dia se torna impossível em função do pequeno tamanho do feto e das estruturas sexuais que são aparentes, mas não detectáveis pelo ultrassom, sendo que a eficácia do ultrassom é de $100 \%$ entre 50 e 110 dias de prenhez (WIDEMAN et al., 1989).

O principal fator limitante da ultrassonografia no presente momento é o alto custo inicial. Treinamento e experiência também são exigidos para obtenção de êxito em termos de interpretação de imagem. Otimizando as técnicas de uso do equipamento ultrassonográfico e aumentando a experiência prática, será possível diagnosticar a idade gestacional e sexagem fetal cada vez mais precocemente (BUCKRELL, 1998). Tornando-se uma prática que, ao ser incorporado ao manejo reprodutivo dos animais de produção, trará vantagens significativas e palpáveis à exploração animal (FERNANDES, 1996).

\section{MATERIAL E MÉTODOS}

O experimento foi desenvolvido nas dependências do Setor de Bovinocultura do sítio das Acácias, na Faculdade Dr. Francisco Maeda - FAFRAM/FE, localizada no município de Ituverava-SP (Figura 1).

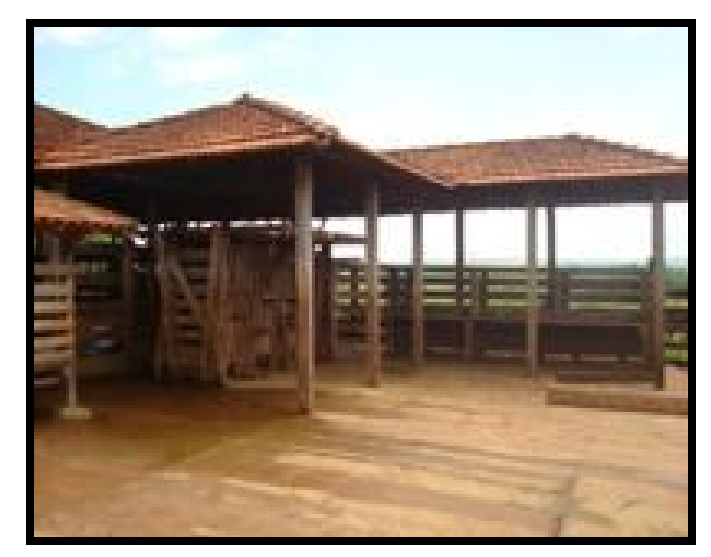

Figura 1: Setor de Bovinocultura, FAFRAM, Ituverava, SP, 2009 
Foram utilizadas 11 fêmeas, da raça Girolando, em idade reprodutiva, pertencentes ao Setor de Bovinocultura Faculdade Dr. Francisco Maeda - FAFRAM/FE, Ituverava, SP, as quais, após a detecção do estro, foram submetidas à inseminação artificial convencional (IA) ou em tempo fixo (IATF), sendo o dia da inseminação considerado o dia zero de gestação. Os animais foram acompanhados durante o período de junho a novembro de 2009. O manejo do Setor, não sofreu nenhuma alteração.

Os animais foram submetidos a programa de inseminação artificial convencional (IA) ou em tempo fixo (IATF), para tanto, foram submetidos previamente a exame ginecológico detalhado para descartar gestação ou afecções do aparelho reprodutor.

Para a IA convencional, as fêmeas foram submetidas à observação de cio duas vezes ao dia, sendo que foram inseminadas 12 horas após a manifestação dos sinais de estro que incluiram a aceitação da monta e presença de muco na vulva.

Para o programa de IATF, que teve início no dia 22 de maio de 2009, as vacas em diestro receberam dispositivo intravaginal a base de progesterona $\left(\mathrm{P}_{4}\right)$, sendo a data da colocação do mesmo foi considerado o dia zero (D-0) do programa, sendo nesse mesmo dia administrado $2 \mathrm{ml}$ de estrógeno $\left(\mathrm{E}_{2}\right)$ por via intramuscular. No dia 30 de maio de 2009, considerado o dia oito (D-8), o implante foi retirado pela manhã, sendo, neste mesmo dia, administrado $2 \mathrm{ml}$ de gonadotrofina coriônica equina (ecG) e $2 \mathrm{ml}$ de prostaglandina (PGF2 $\alpha$ ), ambos por via intramuscular. Às oito horas da manhã do dia 31 de maio de 2009 (D-9), foi administrado $1 \mathrm{ml}$ de estrógeno $\left(E_{2}\right)$, por via intramuscular. Às 15 horas, do dia 01 de junho de 2009 (D-10), foi realizada a IATF (Figuras 2, 3, 4, 5, 6).

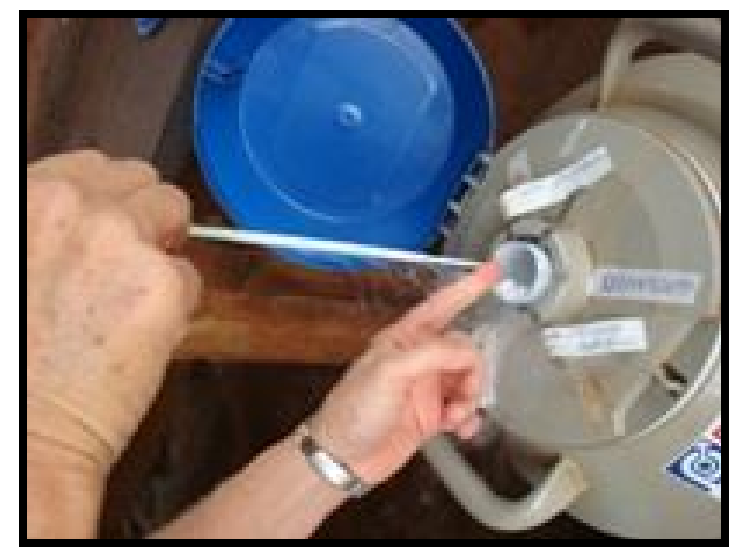

Figura 2: Imagem do botijão de sêmen, Setor de Bovinocultura, FAFRAM, Ituverava, SP, 2009. 


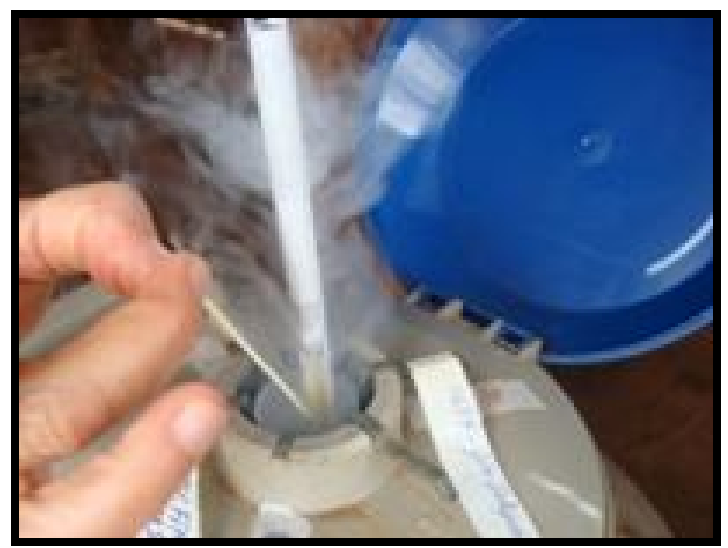

Figura 3: Imagem da palheta contendo sêmen que será utilizado durante a IA, Setor de Bovinocultura, FAFRAM, Ituverava, SP, 2009.

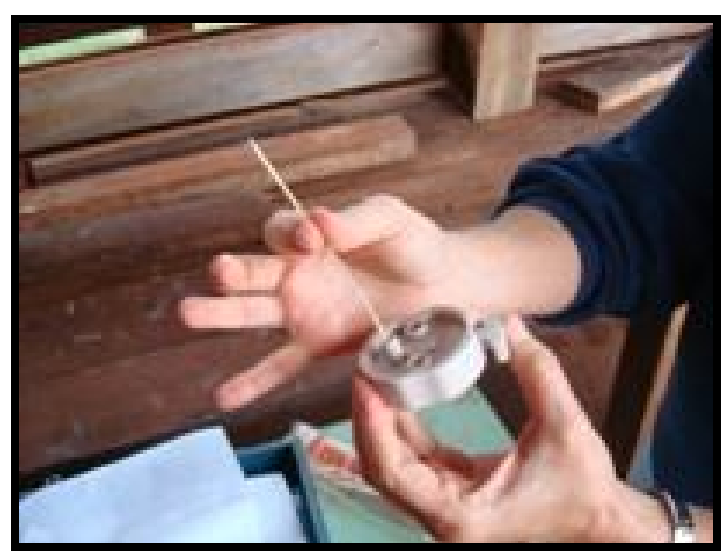

Figura 4: Imagem da palheta sendo cortada para ser adaptada na pipeta de IA. Setor de Bovinocultura, FAFRAM, Ituverava, SP, 2009.

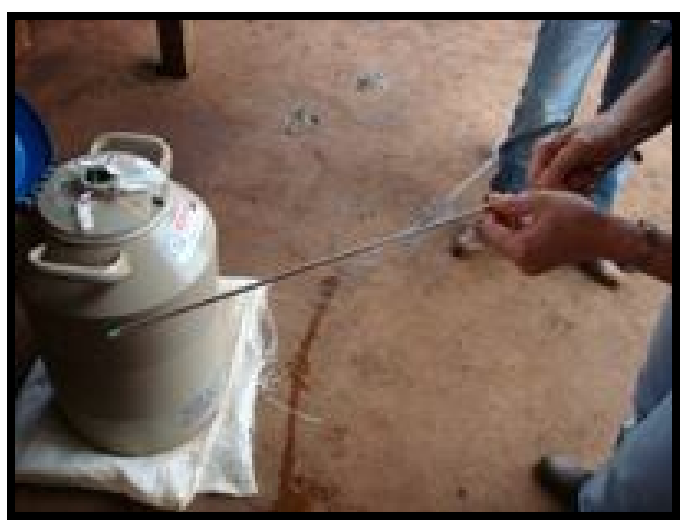

Figura 5: Imagem da palheta sendo colocada no interior da pipeta, para processo de IA. Setor de Bovinocultura, FAFRAM, Ituverava, SP, 2009. 


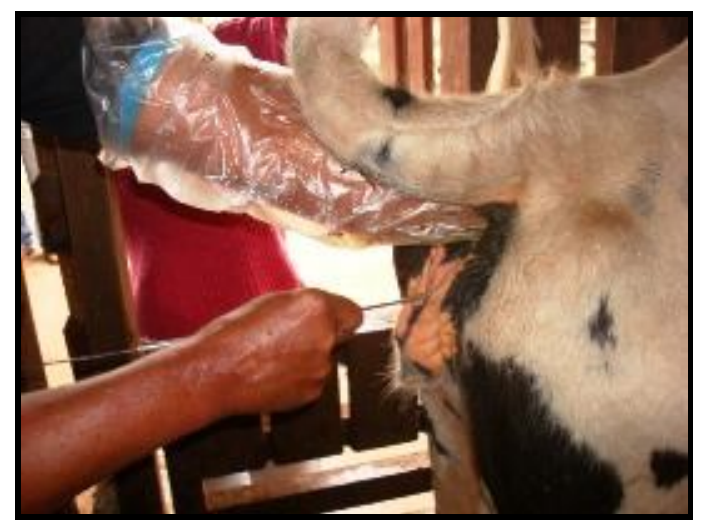

Figura 6: Inseminação Artificial em bovinos, Setor de Bovinocultura, FAFRAM, Ituverava, SP, 2009.

Os exames ultrassonográficos começaram a ser realizados a partir do $26^{\circ}$ dia após a IA, inicialmente para se estabelecer o diagnóstico da gestação seguido do acompanhamento do desenvolvimento embrionário ou fetal até 181 dias de gestação, a cada 14 dias. Os animais foram mantidos em tronco de contenção apropriado durante a realização dos exames ultrassonográficos para que qualquer tipo de acidente fosse evitado (figura 7).

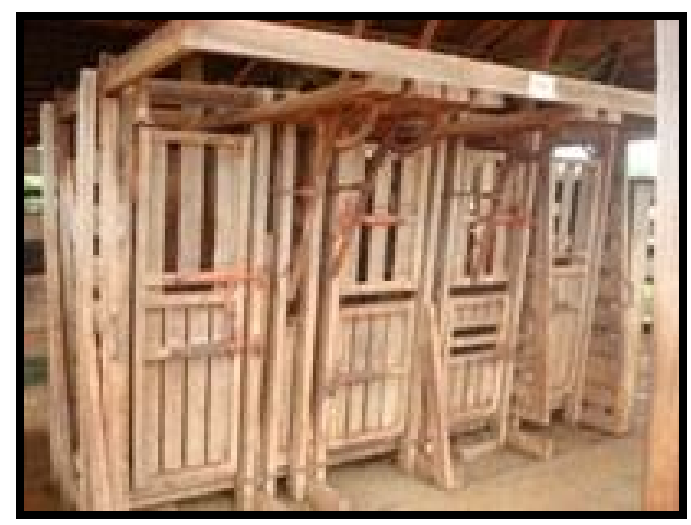

Figura 7: Tronco de contenção, no Setor de Bovinocultura, onde foram realizados os exames ultrassonográficos. Setor de Bovinocultura, FAFRAM, Ituverava, SP, 2009.

Para tanto, foi utilizado equipamento ultrassonográfico da Pie-Medical, com transdutor de 5,0 MHz (Figura 8), posicionado via transretal e previamente lubrificado. Os exames ultrassonograficos foram realizados com intervalos de 14 dias, nos quais foram realizadas fetometria e avaliação da morfologia fetal.

Estabelecer a idade gestacional e e realizar os parâmetros fetométricos avaliados foram os seguintes: vesícula gestacional (VG), diâmetro do placentônio (PLA), comprimento crânio-caudal (CCC), comprimento da escápula (CE), comprimento do fêmur (CF), comprimento do Ílio (CI), comprimento de rádio e ulna (CR), comprimento da tíbia (CT), comprimento do úmero (CU), diâmetro abdominal longitudinal (DAL), diâmetro abdominal transversal (DAT), diâmetro biparietal (DBP), diâmetro inter-orbital (DIO), diâmetro ocular 
(DO), diâmetro occípto-frontal (DOF), diâmetro do tórax (DT), freqüência cardíaca (FC), diâmetro das falanges (FL), comprimento de metacarpo (MEC), comprimento de metatarso (MET);

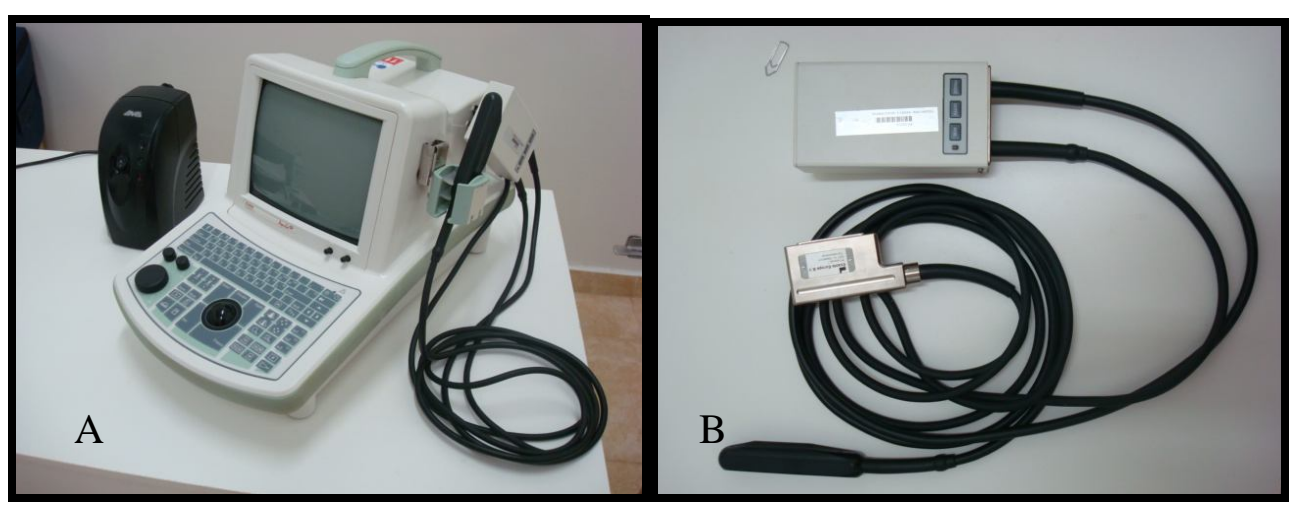

Figura 8: A: Imagem fotográfica do aparelho de Ultrasson Pie-Medical, utilizado para diagnóstico gestacional e mensurações fetométricas. e B: Transdutor de 5,0MHz. FAFRAM, Ituverava, SP, 2009.

Como análise estatística, foram calculadas as médias para cada parâmetro avaliado para cada período de gestação.

\section{RESULTADOS E DISCUSSÃO}

O experimento foi realizado no período de junho a novembro de 2009 , sendo acompanhadas 11 vacas da raça Girolando, inseminadas artificialmente pelo método convencional (IA) ou em tempo fixo (IATF), sendo anotadas as datas e tipo da inseminação e realizado o diagnóstico de gestação de cada animal através do exame ultrassonográfico (Tabela 1). É importante frizar que durante a realização da ultra-sonografia foram realizadas uma média 900 mensurações, sendo utilizados 20 parâmetros diferentes para cada animal. As mensurações eram realizadas a cada duas semanas, num total de 9 dias durante 6 meses, sendo que o objetivo do estudo foi realizar o maior numero de mensurações fetais possíveis.

A duração de cada exame ultrassonográfico por animal variou de 15 à 30 minutos, sendo que o temperamento do animal foi levado em consideração, pois houveram animais que se mantiveram calmos durante a realização da ultrassonografia e outro animais que dificultaram a mensuração de alguns parâmetros.

O temperamento de cada animal demonstrou a imensa necessidade do uso do tronco de contenção, tanto para segurança do animal, quanto para segurança do responsável pela realização dos exames ultrassonográficos. 
Tabela 01: Datas das inseminações, tipo de inseminação e diagnóstico gestacional realizado por ultrassonografia transretal em vacas da raça Girolando acompanhadas no período de junho a novembro de 2009. Setor de Bovinocultura, FAFRAM, Ituverava, SP, 2009.

\begin{tabular}{cccc|}
\hline $\begin{array}{c}\text { Identificação do } \\
\text { Animal }\end{array}$ & Data da IA & $\begin{array}{c}\text { Tipo de } \\
\text { inseminação }\end{array}$ & Diagnóstico de Gestação \\
\hline $\mathbf{1 2 1}$ & $18 / 05 / 2009$ & IA & POSITIVO \\
$\mathbf{1 4 1}$ & $01 / 06 / 2009$ & IATF & POSITIVO \\
$\mathbf{1 5 6}$ & $05 / 06 / 2009$ & IA & POSITIVO \\
$\mathbf{1 7 0}$ & $25 / 03 / 2009$ & IA & POSITIVO \\
$\mathbf{1 7 4}$ & $01 / 06 / 2009$ & IATF & POSITIVO \\
$\mathbf{9 0}$ & $23 / 04 / 2009$ & IA & NEGATIVO \\
$\mathbf{1 0 6}$ & $01 / 06 / 2009$ & IATF & NEGATIVO \\
$\mathbf{1 1 9}$ & $18 / 05 / 2009$ & IA & NEGATIVO \\
$\mathbf{1 2 9}$ & $01 / 06 / 2009$ & IATF & NEGATIVO \\
$\mathbf{1 4 6}$ & $01 / 06 / 2009$ & IATF & NEGATIVO \\
$\mathbf{1 6 5}$ & $19 / 05 / 2009$ & IA & \\
\hline IA: inseminação artificial; & & & \\
\hline IATF: inseminação artificial em tempo fixo & & & \\
\hline
\end{tabular}

Das onze vacas utilizadas durante o estudo, cinco foram submetidas ao uso do protocolo de inseminação artificial em tempo fixo (IATF), e seis à inseminação artificial convencional (IA), valendo salientar que as inseminações foram feitas com sêmen congelado obtido de central de IA idônea, cuja comercialização segue minucioso controle de qualidade. Todas as vacas submetidas á IATF apresentaram estro, o que mostra ótima eficácia do protocolo. Uma vaca com o diagnóstico de gestação positiva aos 28 dias (animal 156); duas vacas com 30 dias de gestação (animal 141 e 174), uma vaca com 46 dias de gestação (animal 121) e uma vaca com 100 dias de gestação (animal 170).

Assim, o exame ultrassonográfico transretal (figura 9) permitiu diagnosticar cinco vacas gestantes entre 28 e 100 dias, sendo três vacas através da inseminação artificial convencional e duas vacas através da inseminação artificial em tempo fixo, ambas com 100\% de eficácia através da visualização da vesícula gestacional (Figura 10). No entanto, o animal 174 abortou aos 110 dias e somente quatro fêmeas puderam ser acompanhadas até a data proposta neste estudo. 


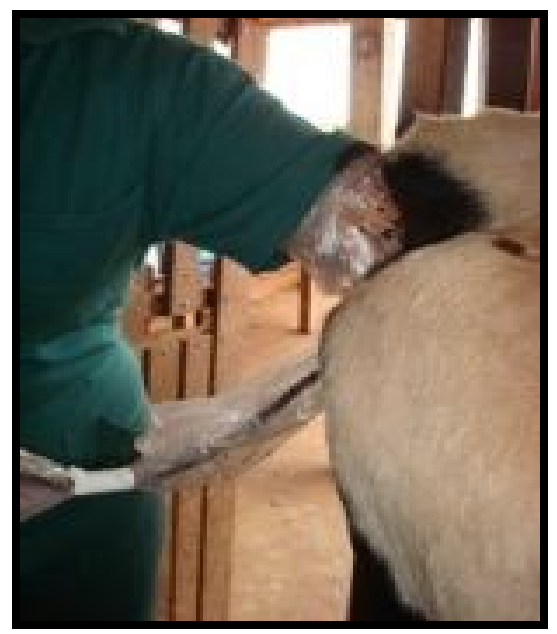

Figura 9: Imagem da realização do exame ultrassonográfico transretal, realizado a cada 14 dias em vacas da raça girolando.Setor de Bovinocultura, FAFRAM, Ituverava, SP, 2009.

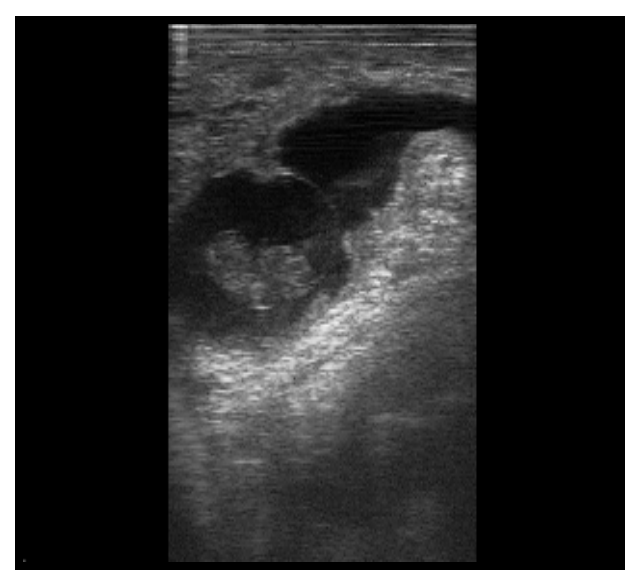

Figura 10: Imagem da Vesícula Gestacional, no destaque o embrião apontado pela seta FAFRAM, Ituverava, SP, 2009.

Foram obtidas, medidas da vesícula gestacional e do feto, sendo mensurados todos os parâmetros possíveis com o intuito de correlacioná-los com a idade gestacional e acompanhar o desenvolvimento fetal. Foi usado transdutor de 5,0MHz. O que permitiu exame com qualidade de imagem, embora também pudesse ser empregadas sondas transretais com freqüência de 5.0, 6.0 e 8.0MHz (Kähn, 1094).

A ultrassonografia em modo-B, itada por vários autores (WIDEMAN et al., 1989; ISHWAR, 1995; LEGA, 2000; HUSSEIN, 2008), mostra-se um método confiável e 100\% eficaz para diagnóstico de gestação ou determinação da idade fetal. Sendo citado por Araújo; Moura (2009), que o uso desta técnica nos animais de produção teve início nos anos 80.

As vantagens da técnica em modo-B relatada por Ishwar (1995) como avaliação em tempo real e a capacidade de registrar imagens paradas, possibilitou a identificação e mensurações fetais do presente estudo (tabelas 2 e 3), sendo um meio eficaz, rápido e satisfatório. 
Tabela 02: Valores médios dos parâmetros fetométricos CCC, CE, CF, CI, CR, CT, CU, DAL, DAT, DBP, obtidos através de exame ultrassonográfico transretal em fêmeas da raça Girolando, acompanhadas em intervalos de 14 dia, compreendidos no periodo de 26 a 225 dias de gestação. Setor de bovinocultura, FAFRAM, Ituverava-SP, 2009.

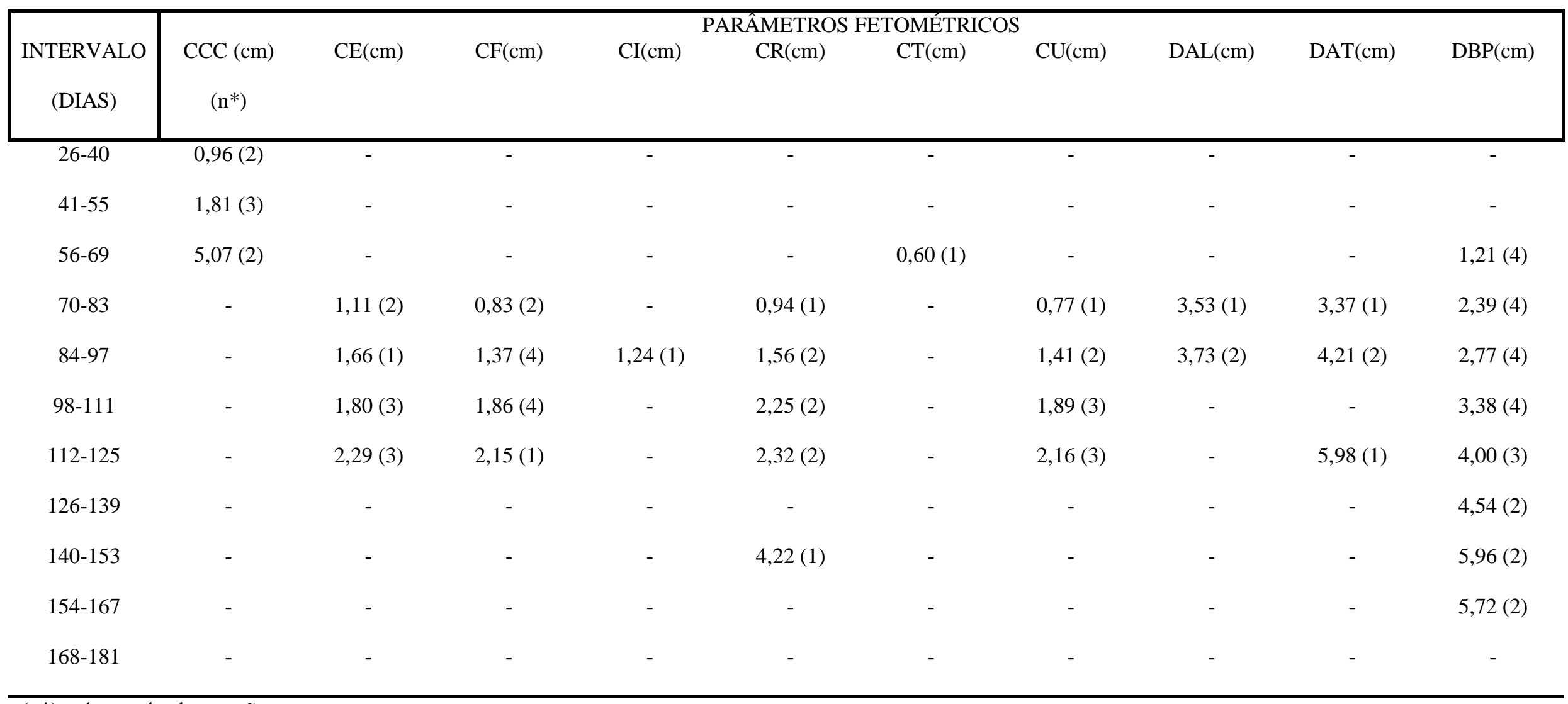

$\left(\mathrm{n}^{*}\right)$ : número de observações

(cm): centímetros 
Tabela 03: Valores médios dos parâmetros fetométricos DIO, DO, DOF, DT, FC, FL,MEC, MET, PLA, VG, obtidos através de exame ultrassonográfico transretal em fêmeas da raça Girolando, acompanhadas em intervalos de 14 dia, compreendidos no periodo de 26 a 225 dias de gestação. Setor de bovinocultura, FAFRAM, Ituverava-SP, 2009.

\begin{tabular}{|c|c|c|c|c|c|c|c|c|c|c|}
\hline \multirow[b]{2}{*}{$\begin{array}{c}\text { INTERVALO } \\
\text { (DIAS) }\end{array}$} & \multicolumn{10}{|c|}{ PARÂMETROS FETOMÉTRICOS } \\
\hline & $\begin{array}{c}\mathrm{DIO}(\mathrm{cm}) \\
(\mathrm{n} *)\end{array}$ & $\mathrm{DO}(\mathrm{cm})$ & $\mathrm{DOF}(\mathrm{cm})$ & $\mathrm{DT}(\mathrm{cm})$ & $\mathrm{FC}(\mathrm{bpm})$ & $\mathrm{FL}(\mathrm{cm})$ & $\operatorname{MEC}(\mathrm{cm})$ & $\operatorname{MET}(\mathrm{cm})$ & $\operatorname{PLA}(\mathrm{cm})$ & $\mathrm{VG}(\mathrm{cm})$ \\
\hline $26-40$ & - & - & - & - & $220(1)$ & - & - & & & $1,88(3)$ \\
\hline $41-55$ & - & - & - & - & - & - & - & & & $3,48(3)$ \\
\hline $70-83$ & - & $1,04(1)$ & - & $2,59(1)$ & $190,3(3)$ & - & - & $0,82(2)$ & $2,12(4)$ & \\
\hline $84-97$ & - & $1,46(2)$ & - & $2,97(1)$ & $180,6(3)$ & $0,38(1)$ & $1,08(1)$ & & $2,95(2)$ & \\
\hline $98-111$ & - & $1,65(4)$ & $4,56(1)$ & - & $176,2(4)$ & - & $1,99(2)$ & & $2,78(2)$ & \\
\hline $112-125$ & - & $2,07(3)$ & $5,06(2)$ & $5,02(1)$ & $156,5(4)$ & - & - & $2,13(3)$ & $3,84(2)$ & \\
\hline $168-181$ & - & - & - & - & - & - & - & & $5,16(1)$ & \\
\hline
\end{tabular}

$\left(\mathrm{n}^{*}\right)$ número de observações

(cm) centímetros

(bpm) batimentos por minutos 
Alguns parâmetros citados por Ramos et al. (2007) foram estudados e utilizados tais, como comprimento crânio-caudal (CCC), mensurado a partir da extremidade superior do crânio até a primeira vértebra coccígea; diâmetro biparietal (DBP) (Figura 11), avaliado como a distância entre os ossos biparietais na secção transversal e a freqüência cardíaca (FC). Tais parâmetros também foram encontrados por Karen et al.,(2008) durante a realização da fetometria em cabras, possibilitando adicionar outros parâmetros como: diâmetro do tórax (DT), diâmetro dos placentônios (PLA), comprimento do fêmur (CF) e diâmetro do cordão umbilical, este último mensurado nesta ocasião.

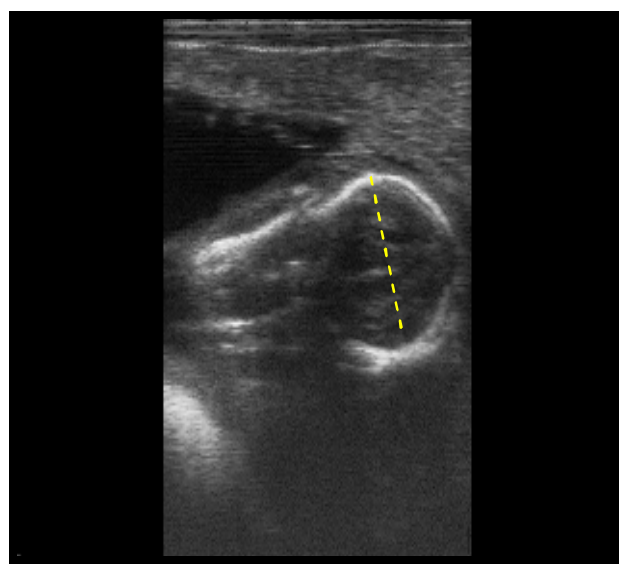

Figura 11: Imagem do Diâmetro biparietal (DBP) aferido em fetos bovinos representado pela linha pontilhada. Setor de bovinocultura, FAFRAM, Ituverava-SP, 2009.

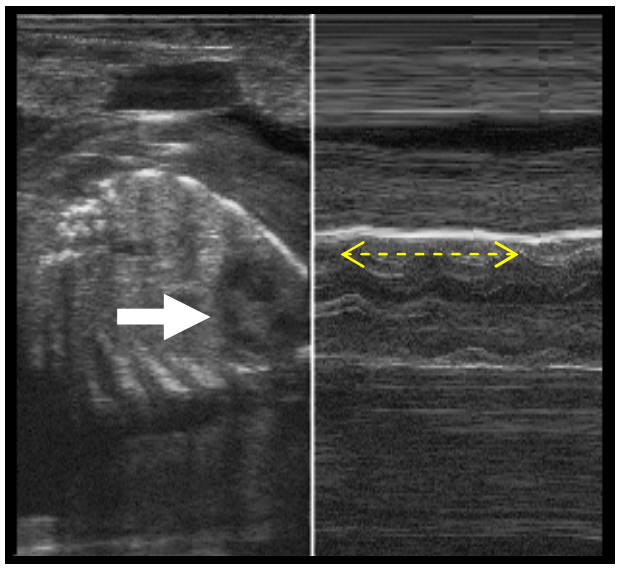

Figura 12: Imagem ultrassonográfica da área cardíaca (seta) de feto bovino e das ondas produzidas pelo músculo cardíaco (<-------->) durante a sístole e diástole, as quais servem de auxílio para aferir a freqüência cardíaca fetal. Setor de bovinocultura, FAFRAM, ItuveravaSP, 2009.

Segundo Hussein (2008), a ultrassonografia pode mostrar resultado precoce e confiável para diagnóstico gestacional entre o $19^{\circ}$ e o $27^{\circ}$ dia após o acasalamento, porém para obtenção de medidas fetométricas somente a partir do $40^{\circ}$ dia de gestação. $\mathrm{O}$ diagnóstico gestacional pode ser feito pela visualização de líquidos intra-uterinos do embrião e/ou da presença de placentônios. Porém, para que o diagnóstico tivesse maior precisão, as fêmeas 
somente foram consideradas gestantes a partir da visualização do embrião, o que ocrre com um período mínimo de 28 dias.

Já os parâmetros fetométricos puderam ser realizados a partir de 32 dias, sendo o CCC com $0,65 \mathrm{~cm}$, o primeiro parâmetro a ser considerado. Sendo que a obtenção das demais medidas durante a realização do presente estudo foram realizadas em maior número e mais facilmente, após o $40^{\circ}$ dias de gestação, coincidindo com os estudos de Hussein (2008).

Aos 40 dias de gestação os batimentos cardíacos foram observados cuja freqüência foi aferida em 22 bpm (figura 12), sendo observado que a freqüência cardíaca diminuiu com a progressão da gestação. Segundo Wolf; Gabaldi (2002), aos 30 dias já é possível identificar os batimentos cardíacos do embrião com frequiência de 150 a 188 batimentos por minuto, permitindo, assim, a verificação de sua viabilidade.

Wolf; Gabalde (2002), referem que no $30^{\circ}$ dia, o diâmetro da vesícula é de 18 a $20 \mathrm{~mm}$ sendo o momento que o feto pode ser bem visualizado e envolto por uma fina linha ecogênica, o âmnion. Com 29 a 33 dias, as cavidades oculares podem ser observadas como áreas anecóicas esféricas em cada lado do crânio; o diâmetro ocular observado na figura 13, foi um dos parâmetros observados em quase todos os exames. Com 29 a 39 dias de gestação os membros torácicos são identificados. E suas mensurações foram facilmente obtidas entre 70 e 125 dias de gestação. Aos 33 a 38 dias, os placentônios são evidenteciados próximos ao feto, como elevações semicirculares. Durante a realização deste estudos, os placentônios(Figura 14) foram facilmente encontrados concordando com os autores retro-mencionados, a partir de 70 dias durante toda a gestação, com mensurações a partir de 70 a 225 dias.

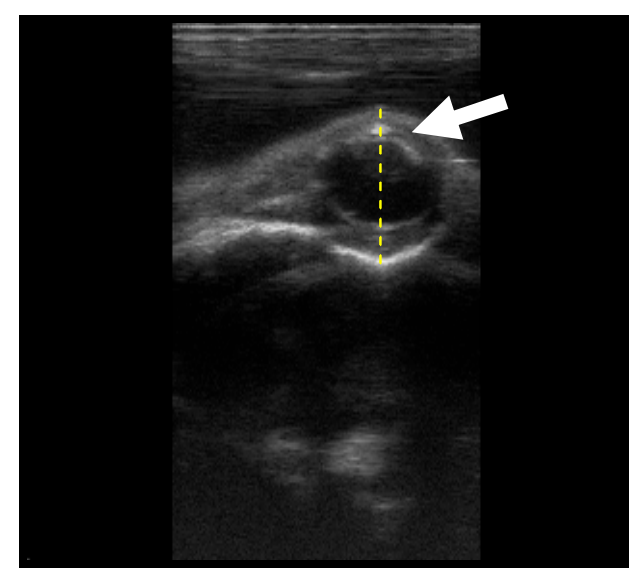

Figura 13: Imagem ultrassonográfica da órbita e do diâmetro orbital (---------) de um feto bovino em secção horizontal.Setor de bovinocultura, FAFRAM, Ituverava-SP, 2009. 


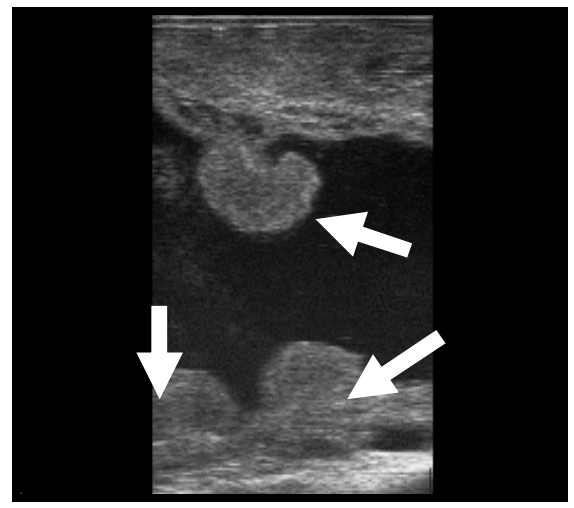

Figura 14: Imagem ultrassonográfica de placentônios (setas) de bovinos. Setor de bovinocultura, FAFRAM, Ituverava-SP, 2009.

A partir do segundo trimestre de gestação, a ultrassonografia do feto ganha importância, pois todos os órgãos podem ser avaliados (figuras 15 e 16). Além disso, entre o segundo e o terceiro trimestre, as característica observáveis do ambiente uterino são os múltiplos placentônios e a diferença de ecogenicidade dos fluidos aminiótico e alantoidiano, visto que o primeiro, devido a riqueza de células, apresenta ecogenicidade maior.(LÉGA, 2007).

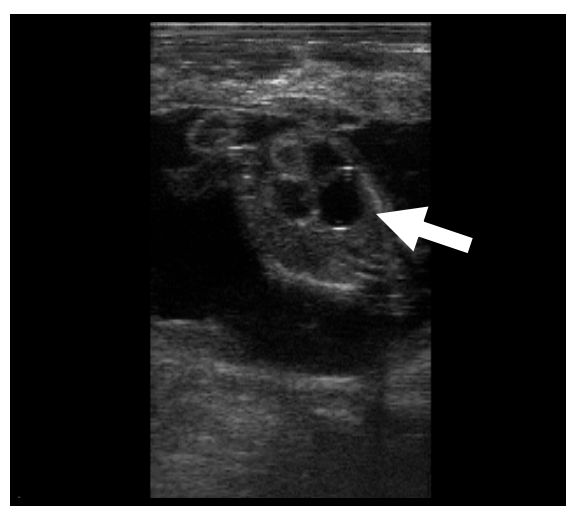

Figura 15: Imagem ultrassonográfica anecóica dos compartimentos gástricos (seta) de um feto bovino em secção horizontal.Setor de bovinocultura, FAFRAM, Ituverava-SP, 2009.

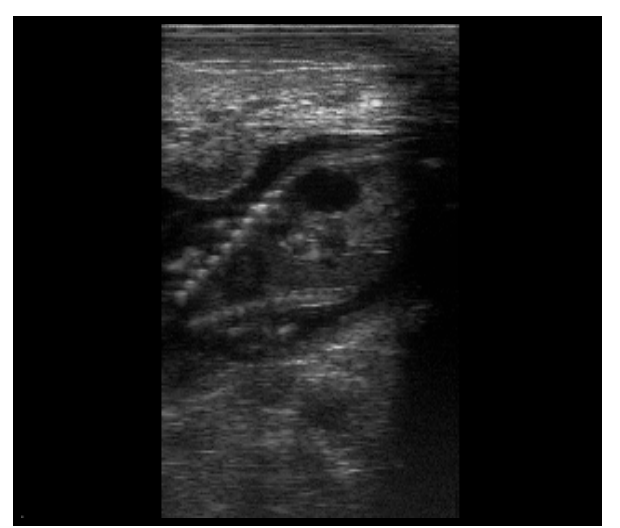

Figura 16: Imagem ultrassonográfica evidenciando, tórax, abdômen e diâmetro torácico de um feto bovino em secção horizontal ). Setor de bovinocultura, FAFRAM, ItuveravaSP, 2009. 
Durante a realização dos exames ultrassonográficos foi possível observar o crânio com acurácia no decorrer dos seis meses de trabalho. (figura 17).

O CCC pôde ser mensurado por um breve período, devido ao limitado alcance das ondas produzidas pelo transdutor e devido ao desenvolvimento e ganho de peso progressivo do feto que alteram a topografia uterina, visualizados e através deles, avaliar a morfologia fetal (WOLF; GABALDI, 2002; KÄHN 1994).

Segundo Kähn (1989), até o final do $4^{\circ}$ mês de gestação, pode-se observar os membros torácicos (figura 18) e membros pélvicos (figura 19) e, para sua mensuração somente as diáfises devem ser consideradas, possibilitando a observação das falanges (figura 20).

Durante o presente estudo os parâmetros mais facilmente obtidos após o início da calcificação fetal são: Diâmetro biparietal (DBP), Comprimento do fêmur (CF), Diâmetro dos placentônios (PLA), Diâmetro ocular (DO), Freqüência cardíaca (FC).

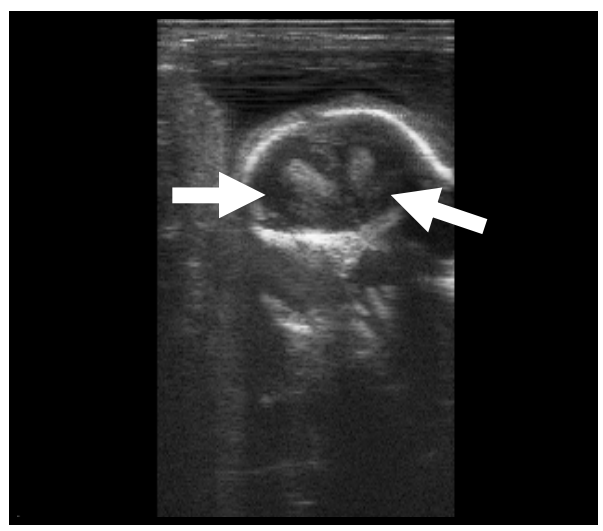

Figura 17: Imagem ultrassonográfica dos hemisférios cerebrais (setas) de um feto bovino. Setor de bovinocultura, FAFRAM, Ituverava-SP, 2009.

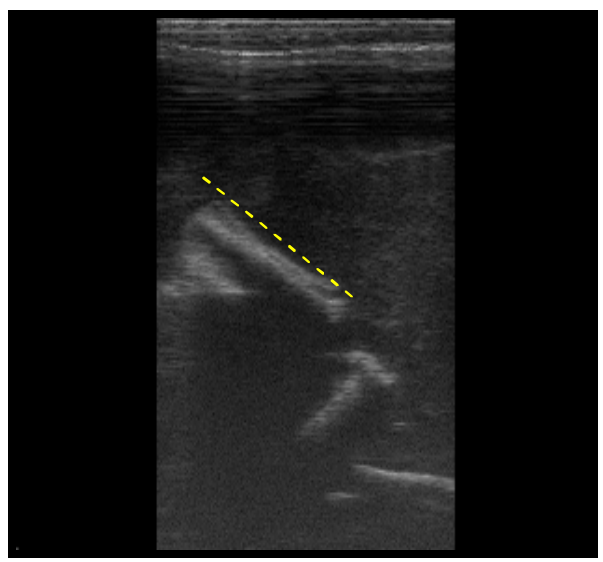

Figura 18: Imagem ultrassonográfica de ossos longos de fetos bovinos. Notar a mensuração do comprimento da escápula (----------). Setor de bovinocultura, FAFRAM, Ituverava-SP, 2009. 


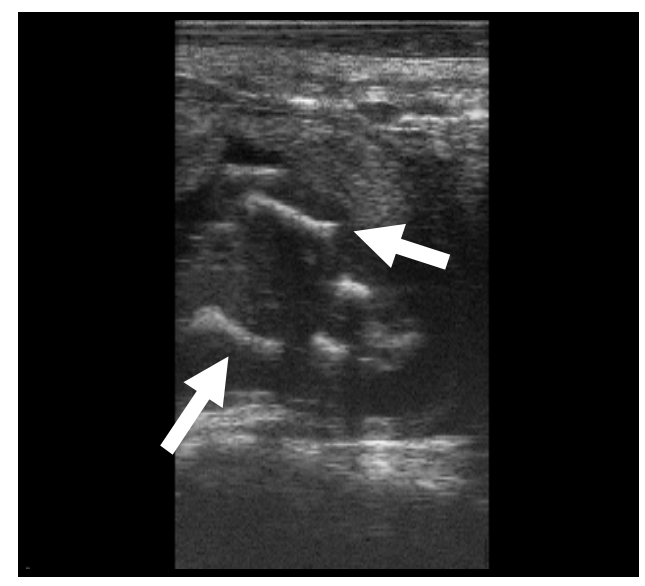

Figura 19: Imagem ultrassonográfica dos membros pélvicos, evidenciando o fêmur (seta) de fetos bovinos. Setor de Bovinocultura, FAFRAM, Ituverava-SP, 2009.

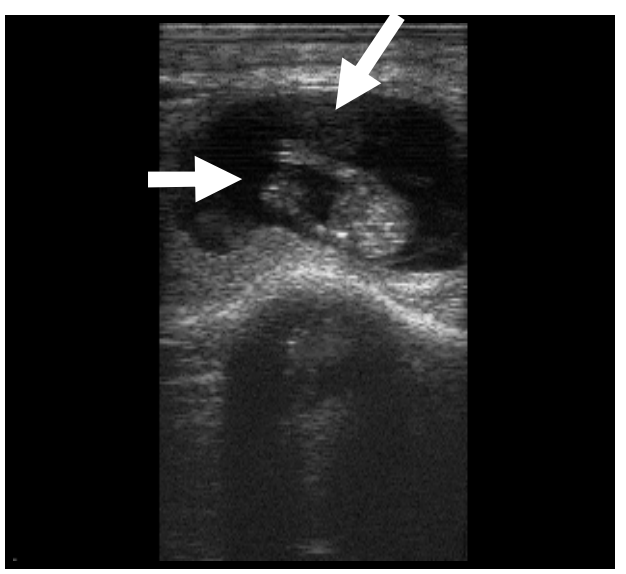

Figura 20: Imagem ultrassonográfica de um feto bovino em secção transversal, evidenciando as falanges dos membros pélvicos (seta). Setor de bovinocultura, FAFRAM, Ituverava-SP, 2009.

Com o avanço do período gestacional e aumento no tamanho das estruturas fetais, bem como, posicionamento ventral do útero, tornou-se mais difícil à obtenção dos parâmetros fetométricos, no entanto o estímulo à movimentação somática fetal pode permitir a avaliação de estruturas do crânio e parte distal dos membros.

Assim, os valores fetométricos foram melhores mensurados até 167 dias de gestação e podem ser utilizados para confecção de fórmulas de regressão para determinação da idade fetal, como estudos futuros.

E, ainda, este estudo permitiu a avaliação da morfologia e do perfil biofísico fetal avaliado pelos movimentos cardíacos e somáticos fetais.

\section{CONCLUSÃO}

É possível concluir através dos resultados obtidos durante a realização desse trabalho que: 
- A ultrassonografia transretal em modo-B é um método eficiente para precocemente diagnosticar a gestação, e acompanhar o desenvolvimento fetal, do $30^{\circ}$ dia até o $6^{\circ}$ mês de gestação.

- A idade gestacional pode ser determinada através da fetometria, sendo que até o $60^{\circ}$ dia de gestação os parâmetros mais eficazes são o comprimento crânio-caudal (CCC) e diâmetro da vesícula gestacional (VG)

- Durante o presente estudo os parâmetros mais facilmente obtidos após o início da calcificação fetal são: Diâmetro biparietal (DBP), Comprimento do fêmur (CF), Diâmetro dos placentônios (PLA), Diâmetro ocular (DO), Freqüência cardíaca (FC).

- Com a realização da fetometria do $30^{\circ}$ dia $180^{\circ}$ dias de gestação, pode-se obter os seguintes parâmetros: vesícula gestacional (VG), diâmetro do placentônio (PLA), comprimento crânio-caudal (CCC), comprimento da escápula (CE), comprimento do fêmur $(\mathrm{CF})$, comprimento do ílio (CI), comprimento de rádio e ulna (CR), comprimento da tíbia (CT), comprimento do úmero (CU), diâmetro abdominal longitudinal (DAL), diâmetro abdominal transversal (DAT), diâmetro biparietal (DBP), diâmetro inter-orbital (DIO), diâmetro ocular (DO), diâmetro occípto-frontal (DOF), diâmetro do tórax (DT), frequiência cardíaca (FC), diâmetro das falanges (FL), comprimento de metacarpo (MEC), comprimento de metatarso (MET).

- O acompanhamento fetal durante o período gestacional, permite-se diagnosticar a viabilidade do concepto, através da anatomia fetal, servindo como método de avaliação de defeitos congênitos.

- A partir do $6^{\circ}$ mês de gestação, as mensurações são dificilmente obtidas devido ao tamanho e peso do bezerro, que se encontra no fundo da cavidade abdominal da fêmea dificultando o posicionamento correto do transdutor.

\section{REFERÊNCIAS}

ABUD, S. F. A. et al., Uso da ultra-sonografia em fêmeas suínas submetidas a acasalamento natural ou inseminação artificial. Nucleus Animalium, v.1, n.1, p.115-128, maio 2009.

A. M. KAREN, E. M. FATTHOUH, S. S. ABU-ZEID. Estimation of gestational age in Egyptian native goats by ultrasonographic fetometru. Animal reproduction science. Disponivel em: <http//www.elsevier.com/locate/anireprsci> Acesso em: 19 out de 2009.

ARAUJO, A. A.; MOURA, A. A. A. Utilização da ultrassonografia no manejo reprodutivo de rebanhos bovinos. Disponível em: <http://www.bovinos.ufc.br/ultrasom .doc>. Acesso em: 12 fev de 2009. 
ASSOCIAÇÃO BRASILEIRA DOS CRIADORES DE GIROLANDO. Disponível em <www.girolando.com.br. Acesso em: 02 fev de 2009.

BALL, P. J. H.; PETERS, A .A. R. Reprodução em bovinos. 3. ed. cap 11, p. 134 - 147. ROCA 2006.

BARROS, B. J. P.; Diagnóstico precoce da gestação, perdas embrionária e fetal e sexagem de fetos pela técnica da ultra-sonografia em bovinos zebus. São Paulo, 1997. p.98.

BUCKRELL, B.C.; BONNETT, B. N.; The use of real time ultrasound rectally for early pregnancy diagnosis in sheep. Theriogenoly, v.25, n.5, p.665-671, 1986.

FERNANDES, T. P. Características ultra-sonográficas em modo-B (tempo real) da gestação na cabra doméstica (Capra hircus LINNAEUS, 1758). São Paulo, 1996. p.96.

GAZITÚA, F. J. et al., Prediction of gestational age by ultrasonic fetometry in llamas (Lama glama) and alpacas (Lama pacos). Theriogenology.

$<$ http//www.elsevier.com/locate/anireprsci> 2000, Acesso em: 19 out de 2009.

GONÇALVES, P. B., et al., Biotécnicas aplicadas à reprodução animal. São Paulo ROCA, 2008, 2.ed. p. 17-32.

HAIBEL, G. K. Real-time ultrasonic fetal head mensurement and gestational age in dairy goats. Theriogenology, v.30, n.6, p.1053 - 1057, 1988.

HUSSEIN A.A. Ultrasonographic assessment of early pregnancy diagnosis, fetometry an sex determination in goats. Theriogenology. $<\mathrm{http} / \mathrm{www}$.elsevier.com/locate/anireprsci $>2008$, Acesso em: 19 out de 2009.

ISHWAR, A.K. Pregnancy diagnosis in sheep and goats: a review. Small Rum. Res. v.17, p.37-44, 1995.

JAINUDEEN, M. R.; HAFEZ, E. S. E. Gestação, fisiologia pré natal e parto. In: HAFEZ, B.; HAFEZ, E. S. E. Reprodução animal. 7 ed. Barueri, SP: Manole, 2004.

JONES, SL, FECTEAU, G. Hydrops uteri in caprice doe pregnant with, goat-sheep hybrid fetuses. J. Am. Vet. Med. Assoc., v.206, n.12, p.1920-1922, 1995.

KÄHN, W. Veterinary reproductive ultrasonography. London: Mosby-Wolfe, 1994. p. 187-210.

LÉGA, E. Acompanhamento ultra-sonográfico transabdominal em modo-B e concentração sérica de progesterona dos primeiros 60 dias de gestação na cabra doméstica (Capra hircus, LINNEAUS, 1758) 2000. Dissertação (mestre) - , Faculdade de Ciências Agrárias e Veterinárias, Universidade Estadual Paulista. Jaboticabal.

LÉGA, Eet al. Determinação da idade fetal por meio da técnica ultra-sonográfica de fetometria e de morfologia fetal em cabras. Arq. Bras. Med. Vet. Zootec. v.59 n.4 Belo Horizonte. Ago.2007. 
MORENO, J. C., CHAVEZ, C.S., BICKHAEDT, K. Fetal rate and real-time ultrasonic fetometry for determination of fetal age in sheep. Deutsch. Tierarztl. Wochensch., v.103, n.11, p. 478-480, 1996

PIETERSE, M. C.; TAVERNE, M. A. M. Hidrometra: diagnosis with real-time ultrasound and treatment with prostaglandins or oxytocin. Theriogenology, v.26, n.6, p. 813-821, 1986. PRESTES N. C.; ALVARENGA, F. C. L.; Obstetrícia veterinária. cap.2, p. 22 - 40. mar. 2006.

RAMOS, A. K. Met al., Avaliação dos Parâmetros Ecográficos de Desenvolvimento Gestacional de Ovinos da Raça Santa Inês. Ciência Animal Brasileira. v. 8. n. 3. p. 537-543. jul./set. 2007.

REICHLE, J. K; HAIBEL, G. K. Ultrasonic biparietal diameter of second trimester Pygmy goat fetuses. Theriogenology, v.35, n.4, p. 689-694, 1991.

SIMOES, J. C. C. Monitorização fetal por ultrassonografia em bovinos de raça Frísea. Trabalho Prático. v. 1, 16p. v. 2, vídeo de 16 minutos. Disponível em: <http://www.veterinaria.com.pt>. Acesso em: 08 fev. 2009.

TONIOLLO, G. H.; VICENTE, W. R. R.; Manual de obstetrícia veterinária; cap 4, p. 36 38. 1993

WINDEMAN, D., DORN, C. G., KRAEMER, D. C. Sex detection of the bovine fetus using linear array real-time ultrasonography. Theriogenology, v31, n.1, p.272, 1989.

WOLF, A.; GABALDI, S. H. Ultra-sonographic accompaniment of gestation in large animals - part II. Ciên. Agr. Saúde. FEA. Andradina. v. 2. n. 2. jul-dez 2002. p 84-89. 